\title{
Territorios baldíos: identidades juveniles indígenas y rurales en América Latina
}

\section{Carles Feixa Pàmpols}

Universitat de Lleida

Feixa@geosoc.udl.es

\section{Yanko González Cangas}

Universidad Austral de Chile

ygonzale@uach.cl

\section{Resumen}

Las teorías sobre la invención histórica de la infancia y la adolescencia se han basado casi exclusivamente en fuentes occidentales (más exactamente centroeuropeas y anglosajonas), por lo que es urgente una reconceptualización en una óptica diacrónica y transcultural. Una de las conclusiones del encuentro "A criança e o jovem na America Latina", que tuvo lugar en Marilia (Brasil) en noviembre del 2001, organizado por la International Sociological Association, fue la necesidad de reconceptualizar la infancia y la juventud desde una perspectiva latinoamericana (como ámbito geográfico, académico y cultural). En este artículo proponemos retomar, en una perspectiva comparativa y como ejemplo de la riqueza y complejidad de las tareas pendientes, dos casos documentales y etnográficos recabados en nuestras propias indagaciones en México (Feixa, 1998b) y Chile (González, 2004a, 2004b), en la idea de comenzar a cursar esta «asignatura pendiente».

Palabras clave: juventud latinoamericana, juventud indígena, juventud rural, construcción sociocultural de la juventud.

\section{Abstract. Wasteland: Indigenous and Rural Youth Identities in Latin America}

The theories about the historical invention of childhood and youth have been almost exclusively based upon western sources (to be more precise, central European and Anglo-Saxon sources). One of the conclusions of the conference "The child and the young in Latin America» ("A criança e o jovem na America Latina»), held in Marilia (Brasil) in November 2001, organised by ISA, was the need to reconceptualise childhood and youth from a Latin American perspective (geographically, academically and culturally). We will focus on a reconceptualisation of youth in a diachronic and transcultural view. We are offering two ethnographic studies from Mexico (Feixa, 1998b) and Chile (González, 2004a, 2004b) as examples of the reconceptualisation that needs to take place.

Key words: Latin-American youth, indigenous youth, rural youth, socio-cultural construction of youth. 


\section{Sumario}

Introducción La juventud en el Chile rural

Referentes para un debate: una pespectiva histórica y transcultural

La juventud en el México indígena

Señales de ruta: a modo de conclusiones

Bibliografía

\section{Introducción $^{1}$}

La liminalidad esencial de la juventud, conjugada con la brevedad mayor o menor de su travesía, es lo que en resumidas cuentas la caracteriza, pero de manera diferente según las sociedades. (Levi \& Schmitt, 1996, I, p. 9)

Una de las conclusiones del encuentro «A criança e o jovem na America Latina» (que tuvo lugar en Marilia, Brasil, en noviembre de 2001, organizado por la International Sociological Association), fue la necesidad de reconceptualizar la infancia y la juventud desde una perspectiva latinoamericana (como ámbito geográfico, académico y cultural), abordando las nuevas formas de ver y vivir estas edades que se configuran con el cambio de milenio (Feixa, 2002). La mayor parte de la literatura desde las ciencias sociales sobre historia de la infancia y la juventud se ha elaborado a partir de la realidad occidental, lo que ha conllevado cierto sesgo etnocéntrico en la conceptualización de la juventud. Desde el trabajo clásico de Ariès (1973), que toma sus datos de la Francia medieval y moderna, hasta la antología más reciente de Levi y Schmitt (1996), pasando por otras obras relevantes (Gillis, 1981; Kett, 1978, Postman, 1990; Mitterauer, 1986; Griffin, 1993), las teorías sobre la invención histórica de la infancia y la adolescencia se han basado casi exclusivamente en fuentes occidentales (más precisamente centroeuropeas y anglosajonas). Entendida como la fase de la vida individual comprendida entre la pubertad fisiológica (una condición natural) y el reconocimiento del estatus adulto (una condición cultural), se ha visto a la juventud como un universal cultural, una fase natural del desarrollo humano que se encontraría en todas las sociedades y momentos históricos. Estas teorías fueron formuladas de manera explícita en 1905 por G. Stanley Hall, un psicólogo norteamericano de formación darwinista, en su monumental Adolescence. Its Psychology and its Relations to Physiology, Anthropology, Sociology, Sex, Crime, Religion and Education (1905). Para Hall:

[...] así como la infancia y la senectud tienen una cierta correspondencia, igual que ocurre en cada etapa de la evolución y la involución individual, y así como la juventud necesita anticiparse a los problemas de la vejez e incluso de la muerte, así también necesitan los jóvenes sentir por anticipado los grandes proble-

1. Queremos manifiestar nuestro agradecimiento a Joaquim Casal y a un evaluador anónimo por los comentarios realizados al texto. 
mas de la realidad, pero de forma no tan seria como para poner en peligro sus almas y el mundo que es mucho más fácil enseñar que volver a encontrar otra vez. (Hall, 1905, I: VI)

Pese a que sus doctrinas fueron vistas como una justificación del carácter universal de la adolescencia, el autor intenta también escapar de planteamientos etnocéntricos. En un largo capítulo dedicado a los ritos iniciáticos ve que "la universalidad de estos ritos y su carácter solemne testifican la importancia crítica de esta edad para casi toda la raza», pero en el primero de los ejemplos que cita — los aborígenes americanos—, reconoce que «la juventud, esta pausa deliciosa entre infancia y madurez, no tiene lugar en su existencia» (ibídem II, 232). En 1928, la antropóloga Margared Mead puso a prueba las teorías de Hall en una sociedad primitiva, mostrando que la adolescencia de las muchachas samoanas no tenía nada que ver con la fase de "tempestad y estímulo" que, según Hall, caracterizaba a esta condición social. En el prólogo al Coming of Age in Samoa, Franz Boas (mentor de Mead) señalaba que «los resultados de esta seria investigación confirman la sospecha largamente alimentada por los antropólogos sobre el hecho de que mucho de lo que atribuimos a la naturaleza humana no es más que una reacción frente a las restricciones que nos impone nuestra civilización» (Mead, 1985: 12-3). El debate sobre la universalidad de la juventud volvería a plantearse en 1973, cuando el historiador francés Philippe Ariès publicó L'enfant et la vie familiale dans d'ancien régime. Basándose en fuentes literarias e iconográficas, el autor postulaba que lo que denominamos "adolescencia» no existía en las sociedades rurales del antiguo régimen; la juventud era una «invención» de la civilización industrial, vinculada a algunas instituciones de la modernidad (como el servicio militar oblitatorio, la escuela pública y la sociedad de consumo):

Nuestra vieja sociedad tradicional se representaba a duras penas la infancia, y todavía peor la adolescencia [...] el niño, a penas físicamente espabilado, era mezclado lo más pronto posible con los adultos, compartía sus trabajos y sus juegos, sin pasar por las etapas de la juventud, que quizá existían antes de la Edad Media y que se han convertido en aspectos esenciales de las sociedades evolucionadas de hoy. (Ariès, 1973: 5-6)

Las tesis de Ariès fueron criticadas por diversos autores, que hicieron referencia a las numerososas sociedades de jóvenes existentes en las comunidades rurales del antiguo régimen, que cumplían una importante función en la organización de las fiestas y los juegos, en el control de los matrimonios y de las relaciones sexuales. Natalie Zemon-Davis (1971), en concreto, estudió las llamadas "abadías de desgobierno" (misrule abbeys), organizaciones de jóvenes extendidas en la Europa central, que tenían encomendadas importantes funciones en el interior de la comunidad, como los trabajos comunales, la organización festiva (el carnaval), el control de la moral sexual (las famosas cabalgatas del asno), de los matrimonios desiguales (charivaris o cencerradas) y de 
la moralidad femenina (rondas y cantos jocosos). Ariès replicó a estas críticas argumentando que, más que de sociedades juveniles, se trata más bien de «sociedades de solteros»: en culturas campesinas donde las nociones de "casa" y «herencia» desarrollan un papel fundamental, el estatus familiar, más que la edad, es la línea divisoria entre dependencia y emancipación.

En 1981, el historiador norteamericano John R. Gillis publicó Youth and History, una de las primeras investigaciones sistemáticas, basadas en archivos alemanes e ingleses, sobre las relaciones de edad en la Europa moderna y contemporánea. Pese a reconocer el valor de la obra de Ariès, Gillis daba la razón a Zemon-Davis en la importancia de las sociedades de jóvenes en la Europa rural:

La jerarquía de las edades — con la infancia, juventud y tercera edad situados en diversos estadios de dependencia de los adultos jóvenes - era de hecho un retrato preciso de la estructura de edades política, económica y social de la sociedad preindustrial, que prescribía dependencia para los niños, semidependencia para los jóvenes y retirada senilidad para los mayores, porque ésta era la única manera de prescribir la transmisión de la cultura, la propiedad y la destreza de generación en generación. (Gillis, 1981: 5)

Lo novedoso no es esta condición social de semidependencia, sino las nuevas imágenes culturales asociadas con esta fase de la vida, que son propias de la sociedad industrial madura. Para Gillis, el «descubrimiento» de la adolescencia se produce en las décadas que van de 1870 a 1900, acontecimiento que se resume en la sentencia boys will be boys (los muchachos han de ser muchachos). Durante la primera mitad del siglo XX, el descubrimiento se extiende progresivamente a las muchachas, a los obreros, a las zonas rurales y a los países no occidentales.

Con posterioridad a este debate, en el último cuarto de siglo, diversos historiadores han abordado el estudio diacrónico de la juventud, en monografías que analizan las raíces del concepto en la sociedad clásica (Grecia y Roma antiguas); la sociedad medieval (Europa de antiguo régimen); la primera sociedad industrial (Inglaterra y los Estados Unidos); los regímenes autoritarios (fascismo, nazismo y comunismo soviético) y la sociedad postindustrial (tras la revuelta estudiantil de 1968). Algunos de estos estudios convergieron en una obra colectiva editada por el historiador italiano Giovanni Levi y el francés JeanClaude Schmidt, que constituye la primera antología sobre la historia de la juventud (Histoire des jeunes en Occident, 1994). Pese a la calidad y utilidad del volumen, los textos monográficos están dedicados todos ellos a la sociedad occidental (en realidad centroeuropea), con incursiones puntuales al Mediterráneo (la Grecia clásica, la Italia fascista) y a los Estados Unidos. Los protagonistas son sobre todo jóvenes estudiantes y urbanos, con informaciones puntuales sobre la clase obrera, las muchachas y el mundo rural (el texto de Daniel Fabre (1996) sobre los jóvenes de "pueblo", constituye una notable excepción). Sin embargo, en todo este debate están ausentes ciertas modali- 
dades de juventud que han sido mayoritarias a lo largo de la historia y que siguen siéndolo en buena parte de las sociedades periféricas y dependientes de los países no occidentales: las juventudes rurales e indígenas. A ellas dedicaremos este artículo, a partir de la presentación de dos estudios de caso localizados en América Latina. Pero antes debemos situar el debate en el contexto intelectual y académico de este continente.

\section{Referentes para un debate: una perspectiva histórica y transcultural}

La juventud que vivís es una fuerza de cuya aplicación sois los obreros y un tesoro de cuya inversión sois responsables. Amad ese tesoro y esa fuerza; haced que el altivo sentimiento de su posesión permanezca ardiente y eficaz en vosotros. Yo os digo con Renan: «La juventud es el descubrimiento de un horizonte inmenso, que es la Vida». (Rodó, 1961: 30)

En América Latina, el comienzo de la atención hacia los jóvenes se remonta a las primeras décadas del siglo XX (González, 2002a, 2002b). Una fase que puede rotularse como de "ensayística», "especulativa» o "creativa», debido a la naturaleza de las obras y los autores que la produjeron. Allí se encuentran gran parte de los intelectuales llamados «nacionalistas latinoamericanos» y sus ensayos emancipadores, prescriptivos o edificantes sobre estos actores. Capitales resultan J. E. Rodó, con Ariel (1900), dedicado a "Los jóvenes de América»; J. Ingenieros, con El hombre mediocre (1913); J. Vasconcelos, con sus múltiples ensayos y cartas (1924); J. C. Mariátegui, con "La reforma universitaria» incluido en Siete ensayos de interpretación de la realidad peruana (1928), o el poeta Vicente Huidobro, con sus artículos y epístolas (1925a, 1925b). Obras y autores que extendieron con la palabra la nombradía juvenil. La «juventud», para el grueso de estos autores, es entendida como un reservorio moral, tanto para la construcción de un «nuevo» y «joven» proyecto civilizatorio en la refundación de la nación y la identidad latinoamericana, como la encarnación de la modernidad cultural, "civil» — Reforma Universitaria de Córdoba, Argentina, en 1918 - y estética (vanguardias artísticas). Preocupan sólo «los» jóvenes (masculinos, de las elites y mesocracias ilustradas) como discípulos, con una misión ética e iluminista. Este proceso se verá interrumpido por el arribo y la legitimidad del positivismo en las ciencias sociales, particularmente en la psicología. Así, ya desde la década de 1930, aparece la figura de Aníbal Ponce como «cientista social» emblemático, con las obras Sicología de la adolescencia (1938) y Ambición y angustia de los adolescentes (1939). Sus obras convergen con la mayoría de las investigaciones que se estaban desarrollando en Estados Unidos y Europa desde principios de siglo en ese campo disciplinario (la influencia más notable en Ponce es la obra de S. G. Hall y los escritos sobre psicología de la infancia y la juventud de Piaget y Spranger).

Las miradas teóricas y los enfoques que diversos investigadores hicieron suyos, básicamente a partir de las décadas de 1950 y 1960 con la profundiza- 
ción modernizante y desarrollista, no van más allá de las posibilidades que las ciencias sociales precariamente institucionalizadas — como la psicología y la sociología-, tuvieron para hacer de la realidad juvenil un fenómeno estudiable. Miradas y enfoques que se prenden de un estructural-funcionalismo norteamericano estigmatizador o de un marxismo sociológico instrumental. El primero preocupado por normalizar a los «jóvenes disfuncionales o desviados» derivados de los procesos de industrialización y migración del mundo rural al urbano y, el segundo, más preocupado por la concienciación de clase y la intervención y fomento de la irrupción de los movimientos juveniles, básicamente estudiantiles. En efecto, como se puede rastrear en los tardíos estudios científicos sobre juventud a nivel latinoamericano, los acentos contenidos agotan un arco de énfasis disciplinarios que van desde las perspectivas psicologistas, que, en un doble aspecto, intentan comprender los fenómenos producidos a nivel individual en los procesos de conformación y búsqueda de la propia identidad y el tránsito fisiológico, todos estos estudios herederos de la obra de E. Erikson (1959, 1971); hasta los enfoques sociológicos influidos por la tradición estructural-funcionalista, herederos de las obras de T. Parsons y R. Merton, que tuvieron una gran presencia desde la década de 1950 en América Latina y que tradujeron a la juventud como "problema». En ellos, fue relativamente mecánica la aplicación del constructo «desviado», "disfuncional» o «anómico», a un segmento de los jóvenes que en ese momento a la sociedad adulta le preocupaba: jóvenes migrantes, delincuentes, alcohólicos, revolucionarios, "hippies» o "rebeldes». Pese a ello, estos aportes extendieron los elementos conceptuales suficientes para entender el «período juvenil» como una forma de socialización y moratoria.

Con el advenimiento de los movimientos sociales y «emancipadores» en las décadas de 1960 y 1970, los estudios sobre juventud comenzarán a ampliarse e institucionalizarse. Será esencialmente la sociología que, la mayoría de las veces, bajo el alero del Instituto Latinoamericano de Planificación Económico y Social, ILPES (dependiente de la CEPAL), se ocupará «oficialmente» de la temática. Las investigaciones científicas inaugurales serán las de Echavarría (1967), Mattelart (1970), Solari (1971) y Gurrieri, Torres-Rivas y otros (1971). La mayor parte de estos estudios estaban focalizados en los procesos de integración y desarrollo social de los jóvenes, intentando sumar dichas situaciones a proyectos modernizadores; como también se detecta un énfasis acusado en indagaciones de carácter político e ideológico en la juventud, básicamente estudiantil. Así, se puede constatar que los estudios sobre la reforma universitaria y los procesos políticos continentales y mundiales desde la perspectiva de la juventud universitaria, monopolizaron la mayor parte de la investigación social sobre estos actores. Tras los estudios comprensivos de Solari $(1967,1968$, 1971), Michelena y Sonntag (1970), Dooner (1974), entre muchos otros, se sucedieron iniciativas regionales que no terminan de culminar hasta nuestros días.

No obstante, tendríamos que convenir que el conjunto de estas obras son marginales con respecto al grueso de las investigaciones socioculturales hechas 
en la región, al menos hasta el Año Internacional de la Juventud proclamado por la ONU en 1985. Los estudios socioculturales habían tendido a ignorar la dimensión generacional: tanto los estudios sobre las comunidades indígenas, como los centrados en sociedades campesinas y urbanas, tendieron a ver a sus sujetos de estudio como indios, campesinos, colonos, hombres, mujeres, burgueses, obreros, pero no como niños y todavía menos como jóvenes. La explicación tradicional a estas omisiones sociohistóricas ponen el énfasis en la inexistencia de las categorías de infancia y de juventud en las sociedades latinoamericanas más allá de algunas minorías sociales (elites y clases medias) y territoriales (zonas urbanizadas). Este supuesto se basa en la concepción generalizada de que la gran mayoría de latinoamericanos y latinoamericanas pertenecientes a las clases y culturas subalternas tienen una temprana incorporación a la vida adulta en términos laborales y sexuales. Esto puede explicar que, a diferencia de lo que ocurre en Europa, los «infantólogos» y los «juvenólogos» no sean comunidades académicas separadas en América Latina. En la segunda mitad de la década de 1980, con la emergencia de la juventudes urbano-populares y el auge de estudios provocados por el citado Año Internacional de la Juventud, estas graves omisiones sociohistóricas y precariedades teóricas comienzan progresivamente a resolverse (Agurto, Canales y otros, 1985; Margulis, 1996; Padilla, 1998; Cubides, 1998; Reguillo, 2001), no obstante, siguen pendientes de indagación sistemática actores sociales invisibilizados (juventudes rurales e indígenas, por ejemplo), que, a contrapelo de la investigación sociocultural, han comenzado a emerger producto de los procesos acelerados de modernización e hibridación cultural. Al mismo tiempo, temas axiales de las investigaciones sobre juventud en la actualidad, no terminan de dilucidarse, a saber: la construcción histórica y cultural de la juventud a partir de la diversidad.

$\mathrm{Si}$ bien es cierto que las apariciones de los jóvenes como actores sociales y sujetos identitarios en América Latina se vislumbra en las primeras décadas del siglo XX (que se expresa particularmente con la Reforma Universitaria de Córdoba de 1918; la producción intelectual de los «nacionalistas latinoamericanos» y la candidatura a la presidencia de la república de Chile por el poeta Vicente Huidobro apoyado por la Convención de la Juventud), no es menos cierto que éstas son expresiones de un prototipo identitario parcial con respecto a la diversidad cultural presente en la región. Prototipo que se extendió a lo largo de casi todo el siglo Xx: jóvenes masculinos, ilustrados y de clases altas o medias. Sin embargo, este prototipo dominante escondió, incluso para los investigadores sociales, las alteridades culturales que se encuentran presentes en el interior de los propios estados nacionales latinoamericanos, fundamentalmente de los pueblos originarios y las sociedades rurales. Aquellos colectivos representan un gran campo de exploración en cuanto a las diversas respuestas simbólicas y materiales en la construcción de sus juventudes. A pesar de que en este reducido espacio nos es imposible solucionar los vacíos detectados anteriormente, creemos que una primera tarea necesaria para dar cuenta de parte del problema es una reconceptualización de las nociones de juventud en 
una óptica diacrónica y transcultural. Por ello, nos proponemos retomar, en una perspectiva comparativa y como ejemplo de la riqueza y complejidad de las tareas pendientes, dos casos documentales y etnográficos recabados en nuestras propias indagaciones en México y Chile (Feixa, 1998b; González, 2004a, 2004b), en la idea de comenzar a cursar esta «asignatura pendiente».

\section{La juventud en el México indígena}

Uno de los rasgos que con mayor frecuencia llaman la atención de los estudiosos de la vida indígena es el tratamiento benévolo y respetuoso que dan los padres a los hijos. Rara vez se educa mediante la violencia física. No se coarta la participación de los niños en la charla familiar. Hay un margen de tolerancia muy amplio para las experiencias sexuales premaritales que abarca, en ciertos grupos, la aceptación de relaciones homosexuales durante la adolescencia [...] En general, se considera adulto al hombre casado, independientemente de su edad. (Bonfil, 1990: 61)

El México "profundo» de las sociedades indígenas (como lo definiera el antropólogo mexicano Guillermo Bonfil) presenta una rica fuente etnográfica para iniciar esta labor. En palabras de Pacheco (1997: 100-101): «en las comunidades indígenas la etapa de la juventud prácticamente no existe. Se pasa de ser niño, perteneciente a una familia y dependiente de ella directamente, a ser adulto, responsable de una familia, ya sea de la propia o de la familia de sus padres». En efecto, en muchas de las lenguas indígenas no existe una palabra que designe específicamente la etapa juvenil, ni instituciones o ritos espaciales para este grupo de edad. Cuando existe una denominación, acostumbra a ser sinónima de un estatus (la soltería) y tiene dos expresiones diferenciadas según el sexo. De hecho, los menores de edad (niños y jóvenes) han tendido a ser invisibles para la investigación antropológica, que ha centrado su mirada en los varones adultos:

Hablar de lo indígena ha sido siempre nombrar a los dirigentes o chamanes, rezanderos o curanderos, artesanos o milperos, mayordomos o macehuales. El indígena de los textos etnológicos casi siempre ha sido un hombre adulto [...] Pero hablar de lo indígena ha significado hablar muy poco de los niños indios; el discurso tampoco ha involucrado a los adolescentes y jóvenes, los que conforman la población del porvenir, lo mismo en términos económicos que culturales. No se ha considerado que también ellos podían tener inquietudes ante la situación de deterioro progresivo y constante de sus esperanzas de superación socioeconómica. (Acevedo, 1986: 7-8)

La utilización de los grados de edad como criterio de distribución del poder político puede ejemplificarse con el sistema de cargos anuales vigente en muchas comunidades tradicionales de indios campesinos de Mesoamérica (Carrasco, 1979). En este sistema, todos los hombres tienen la oportunidad de ascender 
a los escalones superiores y alcanzar el estatus de ancianos o "principales»; el número de puestos es siempre mayor en los escalones inferiores (topiles, recaderos de ceremonias, funcionarios, policías) que en los superiores (regidores, alcaldes y mayordomos). Al parecer, el sistema de cargos fue sobreimpuesto al sistema de educación prehispánico, como las casas de juventud (Telpochcalli) y el seminario (Calmecac) azteca. Los muchachos entraban en las casas de hombres en el escalón más bajo de la escala de grados militares o sacerdotales; cada cambio de grado se señalaba mediante diferencias en el peinado, las ropas y los adornos. Los distintos grupos de edad se reunían en salas distintas del palacio o el templo, participaban en la compleja vida ceremonial, y eran escogidos para determinadas categorías de empleos estatales. Los jóvenes plebeyos entraban en las casas de juventud antes de la pubertad y mientras eran muchachos se encargaban de actividades serviles como barrer o coger leña. Tras la pubertad, eran llevados al campo de batalla, primero como ayudantes, pero luego como guerreros. El éxito en la guerra determinaba su estatus social. Entre los veinte y los treinta años salían de la casa de juventud para casarse.

En el periodo colonial, el sistema de cargos experimenta una serie de cambios. En primer lugar, la institución perdió su vinculación con la guerra y las cosmogonías indígenas: se mantuvo el sistema de ganar prestigio mediante ceremonias, pero en lugar de ofrecer víctimas para sacrificios, se ofrecieron fiestas para los santos patrones. En segundo lugar, se produjo un proceso de ruralización: unas sociedades antes estratificadas se convierten en comunidades igualitarias dentro de un sistema más amplio. Un ejemplo etnográfico nos lo ofrece la comunidad zapoteca de Shan-Dany, Oaxaca (Feixa, 1998b). Descendientes de una civilización prehispánica, los zapotecos son un ejemplo de "primitivización cultural» como efecto del impacto colonial. Don Román es un principal local que ostenta el cargo de presidente del museo comunitario. Evoca su juventud como el duro ascenso por una serie de cargos anuales al servicio de la comunidad:

Desde la niñez me dediqué a ayudar a mis padres, tanto en el campo como a trabajar la lana. Los jóvenes que nacieron entre los años 38 , 40, hasta 50 , su vida fue mucho más difícil que la de los jóvenes de ahora. Desde la edad de diez años, yo ya iba a trabajar como jornalero en el rancho las Carretas [...] Las personas que son nativas de la población de Santa Ana, la costumbre es empezar a dar servicio desde la niñez, por decir algo a los 10 años. El mayor de vara se encarga de ir casa por casa: «Vine a comunicarle que su niño le toca participar con un tercio de leña en esta fiesta que viene». A mí me tocó juntar leña y traerla acá, porque mi padre fue militar y él francamente no nos tuvo consideración: «iÓrale, vayan, porque ese es un servicio, para que se vayan dando cuenta de cómo se vive en una población!». Eso se hacía en tres ocasiones (en tres fiestas). Y ya después nos toca dar también en tres ocasiones rajas de ocote, para participar en esta fiesta que viene en el mes de agosto. Posteriormente, tenemos que apegarnos también a la religión, porque es una herencia que ellos nos están legando, pues: hacer el aseo en una esquina del atrio del templo y colocar una imagen [...] Ya después nos toca prestar servicio como auxiliar 
cuando ya tenemos una cierta edad de 16 años. Ese auxiliar se encarga de custodiar el palacio municipal, los edificios públicos y también dentro de la población hacemos rondines, calle por calle, como si fuéramos los que anteriormente se llamaban serenos en la capital, en Oaxaca. Los jóvenes pueden desempeñar cargos después de ser auxiliar. Yo un año estuve como auxiliar, y al otro, a los 17 años, ya me dieron mi primer cargo, como cabo $1 .^{\circ}$ (Don Román)

Ricardo es un joven de Santa Ana que llegó la semana pasada del «gabacho» (los Estados Unidos). Es un muchacho de veintinueve años inteligente y simpático, que acude con su bicicleta de montaña nuevecita, recién traída de Los Ángeles. Su relato empieza explicando el tradicional sistema de cargos y su relación con la terminología de las edades en zapoteco:

$\mathrm{Al}$ niño cuando nace le dicen badó, es 'nene'. Y al poco tiempo ya le pueden decir kiísh, que quiere decir 'niño' o 'pequeñito'. Así sea mujer o hombre los llegan a denominar igual. Después de esto, a partir de cinco años [hasta los] 20-25, les dicen binin nu-nay: 'está muy joven todavía'. Es binin hasta el instante que no tiene las reacciones de un joven, que podría ser 25, 30, 35. Ya son buín-guul, o buín-ro, que es 'gente madura'. Agu-ro 'ya está grande', ya podría ser de los 15 a los 30 . Y el hombre cuando ya es viejo, a partir de los 60-70, ya les dicen buin-guul. La mujer llega a ser chap, desde que se define su sexo ya con su cabello y todo, desde los cinco años. Pueden recibir ese nombre hasta que llegan a perder la juventud, aun casadas les dicen chap. Hay mujeres que se llegan a casar y a veces se mueren y para decir «Todavía está joven», ellos dicen: "Chap nu-nay». Entonces uno se da cuenta que utilizan esa palabra para decir «joven». Si es mujer madura le dicen gunan-gül. La sociedad aquí, cuando empiezan a decir que un niño es joven, es desde el instante en que empieza a salir, desde que empieza a estar inquieto en su casa, y empieza a preferir amigos que son de fuera de la casa, empiezan a decirle: «Usted ya es un joven que sale, ya debe procurar trabajar más, tienes que darnos más dinero, asearse más, muy pronto va a querer casarse, tiene que procurar hacer su casa». Y eso empieza a partir de los 14, 15, 16 años, que ya son jóvenes. Y si alguien se casa, aunque sea a los 18, aunque sea joven todavía, pueden nombrarlos ya, pueden dar servicios». (Ric)

La gran transformación vino con la masiva emigración de los jóvenes a los Estados Unidos (más del 50\% de los muchachos residen en California y sólo regresan a la comunidad para las fiestas patronales o para buscar pareja):

La emigración ha influido bastante en la sociedad. Empezó como en el 75, que empezaron a emigrar los jóvenes y los señores. Por el 82, 83 comenzaron las primeras fugas en masa. En cada fiesta de agosto se iban muchos jóvenes, porque venía un pariente y se llevaba dos o tres primos, venía en Navidad otra vez y otra vez se llevaba a uno o dos. Antes, en las esquinas abundaban grupitos, simpatizantes de un joven con otro y así. Hoy ya no se encuentra eso, todos ellos están fuera. Antaño había mucho respeto a los mayores: el saludar con las dos manos. Ahorita no tanto, ven un adulto: «Órale!». Los buenos 
modales, los saludos, se están perdiendo, debido a la influencia de la televisión. En la tele se aprenden muchas cosas: el poder casarse y divorciarse, el tener novia y dejarla. Muchas de esas cosas se empezaron a manifestar de allá p'acá. También de la gente que viene de Estados Unidos. Es un fenómeno social que está sucediendo: las influencias exteriores. La mujer trata de modificar sus costumbres y lejos de apreciar los estilos de vida que tienen aquí, los rechaza. (Ric)

La perspectiva de las muchachas es algo distinta: mientras sus coetáneos se van, ellas deben quedarse en la comunidad esperando que las vengan a buscar al cabo de unos años para poder casarse. Mientras tanto, deben ayudar a su familia y abrise camino mediante la educación. Porfiria es una muchacha de dieciocho años que está estudiando el bachillerato profesional. A diferencia de otras jóvenes que he visto en el pueblo, que llevan el vestido tradicional, o al menos el rebozo, ella viste con tejanos y playera, lo que no le libera de las tareas domésticas que deben realizar las muchachas de su edad. Durante una soleada mañana, me refiere la vida de una joven zapoteca, sus actividades culinarias, sus esfuerzos por proseguir los estudios, el respeto debido a los mayores y su crítica a las costumbres que limitan el desarrollo de las mujeres:

Son pocas las muchachas que los padres les dejen estudiar. Es que aquí en el pueblo los padres se imponen: dicen que deberían estar aquí, aprender a hacer tortillas, a moler tejate, a hacer los quehaceres del hogar, y que para qué estudiar, se van a casar y el hombre las va a mantener y no les va a servir de nada. Pero muchas no pensamos lo mismo, pensamos seguir estudiando, tener otro poco de conocimiento para después poder tener otra vida mejor, vemos la situación de nuestros padres como viven ahorita, y también nos ponemos a pensar: si nosotros no estudiamos, nos quedamos como ellos [...] Los jóvenes de aquí se han ido mucho al norte. Como aquí se trabaja duro, ellos se van y les gusta: está muy bonito, hay diversión, no estamos como aquí trabajando en el campo. Antes no se iban las muchachas, solo los muchachos y los señores, pero ya se van. Es que es otra vida. A trabajar más que nada, a ahorrar su dinero, porque sí se gana otro poco de dinero más, como aquí no nos pagan para trabajar. En este mes llegan bastantes del norte, por la fiesta patronal, Santa Ana. Es el 26 de julio, nada más es un día. La persona que le tocó de mayordomo hace un gasto, un convivio para todos en su casa: la gente llega en la mañana, a veces llevan su maicito, mezcal o dinero en efectivo, una guelaguetza que decimos aquí; significa que cuando a ellos les toque hacer un gasto se lo devuelven otra vez. Vienen de Estados Unidos para presenciar la fiesta, convivir con su familia. A veces después de la fiesta se vuelven a ir. (Porfiria)

Otro ejemplo etnográfico nos lo ofrecen los huicholes (Pacheco, 1997). Se trata de un grupo étnico compuesto por unas trenta mil personas, que habitan la sierra madre occidental (estados de Nayarit y Jalisco). Son descendientes de los grupos chichimecas que poblaban el noroeste de México desde la época prehispánica. Durante los cinco primeros años de vida, los niños huicholes 
celebran el Tatei Nayeri, la fiesta en honor a los frutos de la tierra en la que los niños son presentados a los dioses. Cumpliendo las cinco fiestas, se considera que el niño tiene mayores posibilidades de sobrevivir y se convierte en un muchachito. Deja de ser nonutzi (niño) para convertirse en uko (mayor). A partir de esta etapa, los jóvenes son incorporados al trabajo cotidiano asignado a cada género: las muchachas aprenden las labores domésticas junto al resto de mujeres de la familia; los muchachos aprenden las labores del campo junto a los hombres. Los cantadores o marakames del grupo (adultos con poderes mágicoreligiosos) deciden la ocupación de los jóvenes, predeterminándolos para realizar determinados trabajos: músico, cazador, curador, agricultor. En cuanto a las muchachas, a partir de los ocho años se las considera mujeres y se las aparta para matrimonios acordados por los padres. En ocasiones, un cantador viejo las puede pedir en matrimonio, lo que para los padres es un honor. De hecho, las jóvenes carecen de individualidad, lo que se refleja en el hecho de que puedan ser intercambiadas: cuando una mujer comprometida decide escoger otro hombre y huir, su lugar es sustituido por su hermana. Si se acepta el matrimonio, que se hace efectivo en torno a los quince años, se realiza una ceremonia de petición de mano: el futuro esposo debe acarrear leña durante cinco días a la casa de ella; al sexto día, cierran el compromiso fumando un cigarro (el tabaco es símbolo de madurez sexual entre los hombres). Actualmente, en las comunidades huicholes en transición, las que se encuentran más cercanas a los asentamientos urbanos, el papel asignado a los jóvenes está siendo cuestionado por ellos mismos. Al llegar a la adolescencia, una manera de demostrar su inconformidad es huir de casa. Ello expresa la «doble cotidianidad» de la juventud huichola, a caballo entre la tradición y el futuro, entre la comunidad y la sociedad mayor, pues «ser joven significa estar en el tránsito del aprendizaje de la identidad» (Pacheco, 1997: 111-2).

\section{La juventud en el Chile rural}

Entre algunos investigadores de juventud, la invisibilidad es prácticamente total, al punto de que se preguntan: «¿Existe la juventud rural en América Latina?». Por supuesto, se entiende el porqué de la pregunta: si a los 15 años un joven o una joven rural es jefe de hogar, casado y con hijos, y no estudia, sino que trabaja para sobrevivir, parece legítimo suponer que su juventud terminó antes de comenzar. (Durston, 1997: 5)

En el amplio espectro de sociedades basadas en la producción agrícola, ganadera y silvícola, que ocupan un lugar subordinado en conjuntos estatales más amplios, la juventud acostumbra a coincidir con una etapa de semidependencia social, caracterizada por una precoz inserción laboral y por un estatus subordinado de los jóvenes en el seno de la familia. Dado el carácter doméstico de las unidades de producción y consumo, todo está en función de su reproducción material y moral. La dominación patriarcal del cabeza de fami- 
lia sobre los grupos dependientes (mujeres y jóvenes), se expresa en los sistemas de herencia y en el control sexual. Paradójicamente, los jóvenes, que constituyen una parte fundamental de la fuerza de trabajo, no tienen ni prestigio ni poder. Como compensación, ocupan un lugar central en el espacio lúdico de la comunidad y a menudo participan en muchos aspectos de la vida festiva (fiestas patronales) o recreativa (agrupaciones deportivas).

Para dar cuenta de la construcción sociocultural de la juventud en este tipo de sociedades, nos interesaron aquellos presupuestos teóricos que descentran las concepciones identitarias juveniles presentistas (muchas de ellas dicotómicas y estancas) que sólo han visto «jóvenes con o sin juventud» en la historia, fijando su atención sólo en los fragmentos más llamativos y obvios del desarrollo identitario juvenil en América Latina, clásicamente los movimientos estudiantiles de la década de 1960 o las actuales culturales juveniles urbanas. En este sentido, y en base a la idea de continuum identitario (González, 2003), los resultados preliminares de nuestra investigación en base a historias de vida generacionales desde las primeras décadas del siglo XX hasta el presente en el distrito rural costero de Chaihuín (Región de Los Lagos, Chile) ${ }^{2}$, nos muestra abundantes indicios de una conformación identitaria juvenil en transformación, que va desde una tenue adscripción juvenil tensionada por el ciclo vital, pasando por una identidad generacional, hasta la simiente de culturas juveniles ${ }^{3}$. «Edgardo», uno de los actores «biológicamente» más jóvenes entre-

2. Distrito con cerca de mil habitantes dedicado a la recolección de peces y mariscos, labores forestales, pequeña agricultura y, últimamente, al turismo en pequeña escala. Las diferencias agroecológicas y culturales tuvieron un importante papel segmentador de las realidades rurales de la zona central con respecto al sur y centro sur de Chile. Para el caso de la región sur, y específicamente de la región de Los Lagos, el modelo neoliberal impactó fuertemente en la economía y la pequeña explotación agropecuaria, a través de la penetración capitalista de la agricultura comercial, pero lo hizo con intensidad a partir de la década de 1990, con una agroindustria ligada a la pesca (salmonicultura) y al sector forestal. En esta zona geográfica, se evidencian procesos diferenciales desde el punto de vista productivo y geocultural, signados por una población mestiza y mapuche-huilliche importante, un significativo aislamiento y, lo fundamental: una persistencia de economías campesinas y recolectoras de índole familiar que sustentan, vía la fuerza de trabajo estacional, fundamentalmente joven, a las agroindustrias lecheras, agrícolas, forestales y acuícolas.

3. Estos conceptos — «ciclo vital», «identidad generacional» $\mathrm{y}$ "cultura juvenil»— se entienden como parte de un continuum, que va de marcadores identitarios «débiles» (referentes fisiológicos observables, como la primera menstruación, el crecimiento del vello, etc.) a otros más «intensos», que se constituyen como una traducción sociocultural de la edad biológica y remiten a las divisiones socioculturales objetivadas dentro del grupo social en base a atribuciones específicas, definidas por los privilegios, los derechos y las obligaciones, los roles, el comportamiento y la cosmovisión de los sujetos en relación con otros en un momento temporal particular, incluido el campo de representaciones sobre la misma. El concepto de cultura juvenil, por ejemplo, designa la aparición de «microsociedades juveniles» con grados significativos de autonomía de las sociedades adultas que se dotan de espacios y tiempos específicos. Clásicamente, y como referencia paradigmática, serían aquellos jóvenes aglutinados en microsociedades, como las bandas, las pandillas o las tribus, con estilos «espectaculares» surgidos en las urbes metropolitanas, que, corporeizados por la clase, la etnicidad, el territorio y la estética, son creados y recreados por los medios de comunicación masiva y el mercado. 
vistados (diecisiete años), reflexiona sobre estas transformaciones en el contexto de su conversión al estilo juvenil «metalero»:

[...] No soy campesino para comportarme, pero me siento de aquí. Te puede gustar Metallica y ser rural, no es un cambio grande. Cuando me crié aquí no estábamos tan incivilizados como antes, cuando se criaron mis papás. Ahí, por ejemplo, no tenían radio, no podían escuchar música. No sabían nada de grupos. Por ejemplo, escuchaban el nombre de un artista y no estaban ni ahí [no les interesaba], porque no les sonaba, nunca habían escuchado la música hasta como cuando tenían unos veinte años que tuvieron una victrola [fonógrafo manual]. (González, 2004b)

Además, «Edgardo» se explaya sobre los «grupos juveniles» presentes en la comunidad, conformados «por muy pocos chicos [jóvenes]» que él identifica como los «cumbiancheros», «hiphoperos», «metaleros» y «normales». Identifica, además, sus gustos estéticos, prácticas sociales y locus de expresión juvenil, como el recientemente inaugurado negocio de pool [billar], taca-tacas [futbolines] y ping-pong, donde los jóvenes se reúnen asiduamente los fines de semana. No obstante, testimonia también la pugna al interior de su núcleo familiar por dicha adscripción (metalero), considerada «demoníaca» por su madre evangélica (protestante), y su tránsito de regreso al grupo de los «normales». Distinto es el testimonio biográfico de «Heriberto», nacido en 1969, que ubica su corta juventud a mediados de 1980 en el inicio de las transformaciones estructurales de la comunidad, cuando emigró dos meses al pueblo más cercano para realizar un curso de buzo y tuvo la oportunidad de vivir brevemente su identidad juvenil, asistiendo a bares y discotecas:

Pienso que [la juventud] sólo la viví cuando hice el curso de buzo mariscador en el pueblo, no más [...] Nos íbamos con los amigos a la Loloteca, a escuchar música, a cantar, a bailar. Llegaba pura juventud, puros cabros [...] El primer día salimos mareados de adentro, porque era oscuro y tenía de esas luces que van y vienen y dan vueltas. Después nos volvimos para Chaihuín casi alcoholizados tanto salir a carretear [parrandear] [...] Después me junté con mi señora y de ahí pura pega [trabajo]. (González, 2004b).

Las constricciones materiales y simbólicas presentes en la comunidad para vivir la juventud, desaparecen con los cambios producidos en la nueva relación entre el campo y la urbe, la que da paso a la extensión de las experiencias identitarias juveniles deslocalizadas, cuyos antecedentes se vislumbran desde las décadas de 1960, con los abundantes enrolamientos al Servicio Militar por parte de los jóvenes y la alta ocupación en el servicio doméstico urbano por parte de las mujeres jóvenes. Sin embargo, en las décadas posteriores (1980 y 1990) estas experiencias se radicalizan con la neoliberalización del agro, la modernización del transporte y las comunicaciones y la expansión educativa, que hacen a las nuevas generaciones acceder a la enseñanza secundaria, técnico-profesional o al trabajo fuera de la comunidad en pesqueras y buques factorías inter- 
nacionales. La mayoría son experiencias de deslocalización estacional, que implican el regreso e impactan a la comunidad de origen construyendo el fermento de un imaginario juvenil.

En efecto, desde fines de la década de 1980 se produce, en las comunidades del distrito en cuestión, un desfase. El peso de los intersticios de la esfera educativa y el entorno de holganza urbana alimentan en los muchachos y muchachas una condición identitaria «juvenil» definitoria, pero inexistente en términos socioculturales y espacio-temporales en sus localidades rurales de origen. Confinados en los tiempos libres y disponibles en el espacio rural, su experimentación juvenil se ve torpedeada regularmente por la carencia de locus de sociabilidad, interacción, consumo y escenificación de su identidad, que se mueve bajo las coordenadas del encierro, la soledad y la colaboración ocasional en el trabajo «adulto» y sólo interrumpido por las fiestas familiares, torneos de fútbol y celebraciones estivales.

Sin embargo, hacia mediados de la década de 1990, la implementación de un camino y las nuevas vocaciones productivas (asalariados en el sector servicios, empresas forestales y pesqueras), alterarán radicalmente esta dicotomía, forjándose un escenario inédito de interconexión profunda y sistemática urbano-rural, lo que atenuará ostensiblemente la "doble vida» de muchachos y muchachas y dará continuidad a la experiencia identiraria «joven» forjada en la ciudad y la escuela. De este modo, durante la década de 1990, emerge — para un número importante de jóvenes - una ruralidad refundada, concebida más como una adscripción vinculada al territorio que a "un estilo de vida» campesino y recolector, dinamizado por la extensión de las comunicaciones y el naciente turismo. En el principio de la conformación de este nuevo escenario, las muchachas y los muchachos comienzan a viajar asiduamente los fines de semana en el recién inaugurado bus rural al pueblo más cercano - Corral— en busca de las también recién estrenadas discotecas y pubs. Allí suplen las carencias de circuitos de esparcimiento, sociabilidad e interacción con sus pares. Para entonces, Corral ya se había convertido en un destino turístico «obligado» de toda la provincia, al cual viajan regularmente pequeñas y grandes embarcaciones para visitar un castillo fuerte español, bañarse en sus playas cercanas o asistir a la fiesta mayor. La infraestructura turística había crecido a la par y el centro del pueblo ya estaba dotado con numerosos servicios comerciales y lugares de esparcimiento juvenil, entre los cuales, se contaban $-\mathrm{y}$ se cuentandos pubs, locales con videojuegos y la primera discoteca: Zodiac. La discoteca combina la demanda de la población flotante estival con la población juvenil constante en invierno, lo que la hace permanecer abierta todo el año.

Es sintomático que la discoteca aparezca en forma simultánea a los procesos de expansión juvenilizante en la periferia rural, la que conforma un público fiel y constante a su oferta de ocio segmentado. El auge de la discoteca está directamente emparentado con la apropiación de los bienes simbólicos urbanos hechos en forma previa por parte de las muchachas y los muchachos en el contexto educativo, lo que allana el camino para su éxito. Prueba de ello es que en poco tiempo, y hacia 1999, aparece una segunda discoteca en Corral, 
la Danger. La oferta y las posibilidades de transporte más barato y expedito, permiten que muchachas y muchachos puedan acceder fácilmente a las diversas ofertas de esparcimiento, cuyo itinerario lo testimonian varios miembros de esta generación, como Héctor y Catherine:

Lo otro era ir a la discotec [Pueblo Urbano] en micro [bus] y quedarse allá y en la mañana volverse. Ahora hay dos discotecs y hay unos pubs alternativos que tienen música en vivo y ahí uno pasa toda la noche. El ambiente es bueno, por lo menos pa' mi gusto está bien. Para allá iba cuando había plata pescando o cuando llegaba gente a las cabañas. Hay gente que llega en invierno, que le gusta venir a pescar sobre todo. Entonces con esa plata me iba y allá me quedaba [...] hay otros que se amanecen no más por ahí, esperando la micro [bus]. (González, 2004b)

Yo también iba a [Pueblo Urbano], a la casa de mi tía, y con mis primas podía llegar tarde. Íbamos a la discotec Zodiac (ahora hay otra más que se llama Danger). [...] [en la casa de mis primas] hacíamos y deshacíamos. Nos poníamos a tomar, arrendábamos películas para adultos, nos cagábamos de la risa, preparábamos tragos, hacíamos los medios combinados [de alcohol], combinábamos de todo. Lo pasábamos la raja, después nos arrancábamos y nos íbamos a la discotec. [...] . (Ibídem)

La oferta de holganza y diversión juvenil no tardará en engrosarse. Hacia 1998 y con el desarrollo del turismo en el distrito, se comienzan a asentar algunas casas de veraneo (segundas residencias) y lugares de recreación específicamente juvenil en la propia localidad, hecho de enorme significación para las dinámicas identitarias "divididas», en términos espaciales, de muchachas y muchachos. Los «taca-tacas» (futbolines) surgen como una oferta de esparcimiento juvenil en una de las localidades para los visitantes. Sin embargo, al igual que las discotecas de Corral, se mantiene en funcionamiento todo el año debido al surgimiento de actores cada vez más diferenciados al interior de la comunidad, cuya demanda de espacios propios es creciente. Sus dueños diagnosticaron asertivamente dicha necesidad, cuya aceptación fue inmediata. Este elemento pasó de ser un recurso cultural «ajeno» a uno «apropiado», reconvirtiéndose en un elemento propio, de ahí la tolerancia por parte de los pobladores de la comunidad y la ocupación sistemática por sus miembros jóvenes.

La aparición de los «taca-tacas» resume con potencia las nuevas distinciones etáreas procesadas y apropiadas por la cultura local. Es una suerte de «territorio liberado» donde las jóvenes y los jóvenes expresan y escenifican su adscripción como grupo sociocultural diferenciado. Los contenidos iconográficos presentes en sus paredes, como el uso social del espacio (consumo de música, reunión, diversión e interacción), no dejan de ser significativos. Los afiches son una suerte de antología de símbolos juveniles articulados en torno a la música, la política y el deporte. El repertorio cruza temporal y temáticamente toda la historia de las culturas juveniles desde su expansión y diversificación (inicios de la década de 1960), donde se mezclan el Che Guevara y el grupo 
Inti Illimani (paradigmas de las juventudes revolucionarias de los sesenta y los ochenta); Janis Joplin, Pink Floyd y Jim Morrison (modelos de la sicodelia de los sesenta), con AC/DC, formación de Heavy-Metal protagónica de los años setenta y ochenta. A ellos se suman afiches de los clubes de fútbol Colo-Colo, Universidad de Chile y Católica, agrupaciones deportivas que aglutinan con fuerza desde la década de los noventa a hinchas y «barras bravas» juveniles.

La decoración es una hipérbole que subraya la identidad del lugar como articulador de las jóvenes y los jóvenes, y no importa su filiación de estilo o adscripciones estéticas o deportivas. De este modo, la señal es clara: se trata de un centro donde se operacionalizan las diferencias con el resto de la comunidad; se trata, en última instancia, del lugar de «otros», distintos y particulares por su condición etárea y cultural. El contraste en la diacronía visualiza aún más las características de los «tacas-tacas» en relación con su antecedente previo en este distrito rural, los "clandestinos» (bares informales). Estos espacios eran eminentemente intergeneracionales y marcadamente masculinos. La tenue asociatividad de solteros estaba dado más por la exclusión por parte del mundo adulto que por interés propio, lo que en los «taca-tacas» se revierte: son las muchachas y los muchachos que crean y reproducen las diferencias como actores en oposición a los otros segmentos sociales. Esto se plasma en el uso actual de los escasos clandestinos que persisten, los cuales son concurridos mayoritariamente por adultos. De esta forma, los «taca-tacas» cumplen un papel clave en la sustentabilidad de una identidad juvenil crónicamente interrumpida por los estudios, que, situada en el espacio propio, escenifica el gran cambio con respecto a la generación precedente, debido a que ensancha la «exigua juventud» de antaño (léase soltería), como lo afirma Julio:

Los días viernes me venía para acá [comunidad del distrito], de repente estaba desesperado por volver para acá y a veces no. Es que salió el taca-taca y nos juntábamos con el resto de cabros [muchachos] de acá. El ambiente era bueno... "Hola cabros, ¿cómo estuvo la escuela? ¿Juguémonos un poolcito [billar]?». Al rato ya estábamos echándonos algo para la garganta... ¡Ya poh! Y ahí lo pasábamos, terminábamos a las 4 de la mañana y nos veníamos. Y el día sábado era lo mismo, todas las noches. Pero antes, el viernes en la tarde o el sábado, jugábamos una pichanga [pequeño partido de fútbol]. A las 4 de la tarde estábamos cambiándonos de ropa y a las 5 ya estábamos en la cancha jugando. Terminaba la pichanga como a las 7 , nos bañábamos y pelábamos [corríamos] al taca[-taca]. (González, 2004b)

Aunque el apogeo de los «taca-tacas» es en período estival, donde confluyen los miembros que han estado afuera trabajando, los propios muchachos $y$ muchachas que estudian y laboran allí mismo o los parientes que vienen de visita y algunos turistas; es en el invierno donde cumplen su papel más importante, en la medida que permiten sostener la continuidad de una identidad juvenil fragmentada por las (in)migraciones crónicas. A él recurren todos los jóvenes de la comunidad a «matar» el tiempo libre. Allí escuchan y comparten música, conversan, beben, fuman y expresan sus diferencias estéticas y de estilo que van 
desde el reggae (gusto preferente del muchacho que administra el espacio), pasando por la cumbia sound, el heavy metal, hasta el hip-hop y el canto nuevo. Estilos que asocian y disgregan a unos muchachos con respecto a otros, y cuya dinámica se configura en la simiente de culturas juveniles en el «lugar».

El contraste sólo se aprecia en la diacronía. Cerca de sesenta años antes que «Edgardo» tuviera su experiencia metalera, don «Pascual» — nacido en 1929— sabía que su tránsito hacia la emancipación familiar y, por tanto, al término de su condición de "cabro» (niño muchacho), tenía fronteras biológicas muy precisas, prescritas por la propia comunidad de Chaihuín:

[...] según el reglamento, el hombre tenía que tener 25 años pả poderse casar, porque tenía que ser un hombre maduro, que sepa hacer todo lo que había en un hogar. Hacer su casa, sobre todo eso es lo que se exigía en esos años. No podía ser más joven, porque 18, 20 años para los antiguos era un niño todavía; aunque eran más maduros, porque un cabrito de 10 ó 12 años comenzaba a trabajar en el monte, a trabajar con bueyes, que sé yo. Pero en esa época sólo después de los 25 se podía casar. (González, 2004b)

Así, lo importante es que no sólo la soltería articulaba su «niñez juvenil», sino que el dato vital se convertía en imprescindible para cambiar de estatus sociocultural, cuestión que el «joven» esperaba con ansias. El guarismo de 25 años aparece quizás como una muy conveniente negociación para el poder paterno dominante en relación con sus hijos, que, pese a cumplir duras tareas productivas, su dependencia se veía bastante alargada en el tiempo. Sin embargo, no puede haber una mejor transacción para éstos últimos, puesto que el momento de la «liberación» tiene un límite objetivo que no da lugar a priori a la ambigüedad y la coacción por no abandonar la familia (fenómeno que don Pascual vivió intensamente antes de los 25 años). La recompensa a esta larga espera no era menor, porque significaba, en la mayoría de los casos de su generación, la obtención de tierras y materiales para la construcción de una vivienda.

Pese a que estos relatos son mayoritariamente masculinos y que necesitan de una contextualización más profunda para ser comprendidos a cabalidad (lo que excedería en mucho el marco de este artículo), lo relevante es que estos testimonios se inscriben en el escenario de una comunidad rural todavía bastante "clásica» desde el punto de vista de su definición estructural: relativamente aislada, ocupación predominante en tareas agropecuarias y de pesca artesanal (todavía con una acusada economía campesina), reducida disposición de servicios, escasa población, etc. Sin embargo, imbuida en un proceso acelerado de hibridación cultural, producto del cual se han generado respuestas eclécticas en cuanto a la producción y adscripción identitaria juvenil, tensionadas fuertemente por los bienes simbólicos urbanos y las contracciones estructurales propias de la ruralidad, como en nuestro segundo caso (Heriberto), la temprana incorporación al trabajo asalariado - pesca y labores agrícolas - y la migración temporal en busca de empleo y formación, que se mantienen hasta ahora. Así, lo que muchos de estos testimonios ejemplifican con claridad son las abruptas transformaciones de los locus de experiencia identitaria juvenil y los recursos 
culturales y materiales disponibles para vivirla. Con todo, se visualiza, al menos desde el punto de vista biográfico, aquellas huellas intersticiales donde se alojan identidades juveniles omitidas, tanto desde el punto de vista subjetivo, como en un rango mayor: su corporeización en actores sociales.

En este sentido, en la constitución de las juventudes rurales como actores sociales, muy significativas aparecen las transformaciones modernizadoras, tanto en la urbe como en los propios espacios rurales y sus intermediaciones y relaciones. La mercantilización del agro o «modernización» (Gómez y Echeñique, 1988); la consolidación del sector agroindustrial y empresarial y, de sobremanera, la descampenización hacia abajo (proletarización) y el debilitamiento de amplios sectores agrícolas subordinados (campesinos y pescadores con economías de autosubsistencia), han provocado un proceso simultáneo de visibilización mayor por parte de investigadores y planificadores, como de los sujetos mismos, que se expresan con más intensidad en el contexto de la agricultura capitalista que en la de economías campesinas o de autosubsistencia, tal como se demuestra en la organización de cooperativas de producción y comercialización, microempresas y otras organizaciones lideradas y compuestas por jóvenes, que reivindican su condición de tales (en el caso de Chile, con el Servicio Rural Joven de INDAP o, a nivel Latinoamericano, con las múltiples asociaciones afiliadas a la Red Latinoamericana de Juventudes Rurales, RELAJUR). No obstante, las fricciones «rururbanas», comienzan a desvelar con fuerza no sólo a estos jóvenes organizados dentro del campo, sino también a los subordinados y actualmente más omitidos, aquéllos a los que les ha recaído la juventud como imaginario y "como forma forzada» (Rama, 1986: 114), sin espacios materiales para vivirla, desocupados, subocupados, sin tierras ni capitales.

\section{Señales de ruta: A modo de conclusiones}

La juventud retrata siempre, con trazos fuertes, a la sociedad global, la cual, por su parte, no siempre gusta de verse así retratada. (Aranguren, 1985: 22)

En su contribución al monográfico que la revista PAPERS dedicó a la juventud en 1985 (y que el presente número pretende conmemorar), J. L. Aranguren reflexionaba sobre la metamorfosis de la juventud europea, 25 años después de publicar su célebre ensayo de 1961. A una época en que la juventud se convirtió en "referencia, modelo y hasta "moda" para las demás edades" (1985: 19), le sucedió otra en la que los jóvenes dejaron de influir en la decisiones políticas; del «aburrimiento de unos cuantos marginales» se pasó a «la desesperanza de un número muy considerable, y cada vez mayor, de marginados» (p. 22). En el camino, los jóvenes estudiantes dejaron de estar en el centro del escenario y dieron paso a otras formas de ser joven que venían de la periferia (territorial y cultural).

Aunque parciales, las exploraciones anteriores sobre la construcción de la juventud en parte del México indígena y el Chile rural, pretenden dejan tras de 
sí un vasto campo de indagación que ha sido escasamente transitado en América Latina. La ausencia acusada de estudios sistemáticos sobre estos actores, que supere la mirada estructural y macrosocial (así como la instrumentalización populista o desarrollista), ha impedido la generación de aportes teóricos y empíricos sobre los contenidos específicos que supone la emergencia y consolidación de estas identidades juveniles. Gran parte de los supuestos definitorios sobre la conformación de una juventud «indígena» o "campesina», las más de las veces aparecen como una «imposición identitaria», con asideros parcialmente empíricos, debido a que estas adscripciones no han sido indagadas o lo han sido residualmente y de la peor forma posible: esencializándolas. Estos colectivos juveniles se perciben no como actores en sí, sino como "promesas demográficas», como futuros adultos campesinos o indígenas que deben asegurar la reproducción de su sociedad y la continuidad de sus estilos de vida.

En este sentido, las señales de ruta inscritas en estos territorios baldios - desde el punto de vista de la falta de cultivo por parte de los investigadores sociales y de la desatención institucional- pretenden llamar la atención sobre la urgente necesidad de conocer los dispositivos diferenciales en los que se asienta la condición juvenil de estos actores, tanto históricamente, como en los actuales procesos acelerados de transformación estructural y cultural, en los que tanto los «centros» como las «periferias» participan en mayor o menor medida de la globalización. Por una parte, esto conlleva un necesario aporte a las teorías contemporáneas sobre la juventud, que tienen como correlato las metrópolis y la sociedad urbana, dejando al margen no sólo al mundo rural e indígena, sino también a espacios geográficos y culturales duales o híbridos desde el punto de vista social y territorial. Por otra parte, la puesta en circulación de otras visiones teóricas que superen las perspectivas restrictivas y «urbanizantes» sobre la identidad juvenil, debieran contribuir a visibilizar a actores omitidos, tanto por la sociedad mayor (y sus políticas sociales), como de los propios colectivos indígenas y rurales. La toma de conciencia por parte de estos colectivos para comprender esta condición juvenil, implica desvelar una legitimidad identitaria equiparable a la de género, la étnica, o la de clase, lo que incide en la desconstrucción de los estereotipos, la apertura de espacios formales e informales de participación. Se trata, en suma, de proponer una nueva forma de ver la «ciudadanía» en la América Latina del siglo XXI: ya no sólo como un proceso de «incorporación» al estado nación de los sujetos y los grupos históricamente marginados (vistos como un todo culturalmente homogéneo), sino como un proceso de «incorporación» de las diferencias - también las generacionales- a las nuevas identidades democráticas —nacionales y transnacionales- en construcción ${ }^{4}$.

4. Mientras este texto estaba en proceso de edición, han aparecido dos libros colectivos que constituyen avances en esta dirección: una primera aportación al debate sobre la historia de los jóvenes en América Latina (Caccia-Bava, Feixa y González, 2004) y una documentada revisión sobre el papel de los jóvenes en la historia contemporánea de México (PérezIslas y Urteaga, 2004). 


\section{Bibliografía}

ACEVEDO, C. (1986). Estudios sobre el ciclo vital. México: INAH.

AgurTo, I.; CANALES, M. y otros (1985). Razones y subversiones. Santiago: ECO/FOLICO/SEPADE.

Aranguren, J. L. (1985). "La juventud europea a lo largo de cuarenta años». Papers: Revista de Sociología, 25. Barcelona, p. 19-22.

ARIÈs, P. (1973). L'enfant et la vie familiale sous l'ancien régime. París: Seuil. Versión castellana: El niño y la vida familiar en el antiguo régimen. Madrid: Taurus, 1990.

BonfIL, G. (1990) [1987]. México profundo. México: Grijalbo.

Caccia-Bava, A.; FeiXA, C.; GonZalez, Y. (eds.) (2004). Jovens na América Latina. Sao Paulo: Escrituras.

CARrasco, P. (1979). "La jerarquía cívicorreligiosa en las comunidades de Mesoamérica». En LloberA, J.R. (ed.). Antropología política. Barcelona: Anagrama, p. 323-340.

Cubides, H. J.; Laverde, M. C.; Valderrama, C. E. (eds.) (1998). "Viviendo a toda». Jóvenes, territorios culturales y nuevas sensibilidades. Santafé de Bogotá: Fundación Universidad Central.

DoOner, P. (1974). Los movimientos universitarios. Santiago: CPU.

Durston, J. (1997). «Juventud rural en Brasil y México. Reduciendo la invisibilidad». Ponencia presentada en el XX Congreso de la Asociación Latinoamericana de Sociología (ALAS). São Paulo.

ERIKSON, E. (1959). Identity, and the life cycle. Nueva York: International University Press.

- (1971). Identidad, juventud y crisis. Buenos Aires: Paidos. Versión inglesa: Identity: Youth, and crisis. Nueva York, 1968.

FABre, D. (1996). "Forjar la juventud” en el pueblo». En LEVI, G.; SCHMiTT, J.-C. (eds.). Historia de los jóvenes. Madrid: Taurus, vol. II, p. 61-100.

FEIXA, C. (1988). La tribu juvenil. Una aproximación transcultural a la juventud. Turín: L'Occhiello.

- (1998a). De jóvenes, bandas y tribus. Barcelona: Ariel.

- (1998b). El reloj de arena: Culturas juveniles en México. México: Causa Joven.

- (2002). "La construcción social de la infancia y la juventud en América Latina». Red de Estudios sobre Infancia y Juventud de America Latina, Universidade Estadual de Sao Paulo (Brasil). www.marilia.unesp.br/seminario/reijal.html (visitada el 5 de febrero de 2005).

GiLlis, J. R. (1981). Youth and History: Tradition and Change in European Age Relations, 1770-present. Nueva York: Academic Press.

GÓMEZ, S.; ECHENIIQUE, J. (1988). La agricultura Chilena. Las dos caras de la modernización. Santiago: FLACSO.

GONZÁLEZ, Y. (2002a). "Que los viejos se vayan a sus casas: Juventud y vanguardias en Chile y América Latina». En FeIXA, C.; Costa, C.; SAURA, J. (eds.), Movimientos juveniles: De la globalización a la antiglobalización. Barcelona: Ariel, p. 59-91.

- (2002b). Privilegio y omisión: Identidades juveniles en Chile. (De las vanguardias a las juventudes rurales). Tesis de Maestría en Antropología Social y Cultural. Universitat Autònoma de Barcelona.

- (2003). "Juventud rural: Trayectorias teóricas y dilemas identitarios». Nueva Antropología, vol. XIX, no 63. México DF, p. 153-175.

- (2004a). «Óxido de Lugar: ruralidades, juventudes e identidades». Nómadas, n 20. Universidad Central de Colombia, p. 194-209. 
- (2004b). «Edgardo, ex metalero rural»; «Heriberto: mi juventud duró un mes y medio"; "Julio: Vamos a bailar una cumbiamba, decíamos nosotros", "Catherine: Búsquenme ahora que tengo un hijo», $\mathrm{y}$ "Don Pascual y la ley de los veinticinco», relatos de vida. En Oxidos de identidad: Memoria y juventud rural en el sur de Chile (1935-2003). Tesis de doctorado en Antropología Social y Cultural, inédita. Universidad Autónoma de Barcelona.

GRIFFIN, C. (1993). Representations of Youth. The study of youth and adolescence in Britain and America. Londres: Polity.

GURRIERI, A.; TORRES-RIVAS, E. y otros (1971). Estudios sobre la juventud marginal latinoamericana. México: Siglo XXI Editores/Editorial Universitaria.

HaLl, S. G. (1915) (1904). Adolescence: Its Psychology and its relations to Psysiology, Sociology, Sex, Crime, Religion and Education. Nueva York: Appleton Century Crofts.

Huidobro, V. (1925a). «Balance Patriótico». Acción, 6 de agosto, p. 1-2.

- (1925b). "Carta de Vicente Huidobro». Espiga, Quillota, 3. [Puede leerse esta carta en www.uchile.cl/cultura/huidobro (visitada el 5 de diciembre de 2000).

KetT, J. F. (1977). Rites of Passage. Adolescence in America, 1790 to the present. Nueva York: Basic Books.

LeVI, G.; SCHMITT, J.-C. (eds.) (1996) (1994). Historia de los jóvenes. Madrid: Taurus, 2 vols.

Margulis, M. (ed.) (1997). La juventud es más que una palabra. Buenos Aires: Biblos. Mariategui, J. C. (1988). Siete ensayos de interpretación de la realidad Perurana. Barcelona: Crítica-Grijalbo. Original de 1928 (Lima: Biblioteca Amauta).

MatTelart, M. (1970). Juventud chilena: Rebeldia y conformismo. Santiago: Ed. Universitaria.

Mead, M. (1985). Adolescencia, sexo y cultura en Samoa. Barcelona: Planeta (Coming of Age in Samoa, 1928).

MEDINA ECHAVARRIA, G. (1967). La juventud latinoamericana como campo de investigación social. México: Siglo XXI.

MitTERAUER, M. (1986). I giovani in Europa dal Medioevo a oggi. Roma-Bari: Laterza. Musgrove, F. (1964). Youth and the Social Order. Londres: Routledge \& Kegan Paul.

PACHECO, L. (1997). «La doble cotidianeidad de los Huicholes jóvenes». Jóvenes, 4. México, p. 100-112.

Padilla, J. (ed.) (1998). La construcción de lo Juvenil. México: Causa Joven.

Pérez-Islas, J. A; Urteaga, M. (eds.) (2004). Historias de los jóvenes en México: Su presencia en el siglo XX. México: Secretaría de Educación Pública, Instituto Mexicano de la Juventud, Archivo General de la Nación.

Ponce, A. (1960) [1938]. Psicología de la adolescencia. México: Manuales UTEHA (Unión Editorial Tipográfica Hispanoamericana).

- (1939). Ambición y angustia de los adolescentes. Buenos Aires: Talleres Gráficos L.J. Rosso.

Postman, N. (1990). The End of Childhood. New York: Basic.

Rama, G. (1986). «La juventud y el Futuro». Revista de Estudios sobre Juventud, 20. Madrid, p. 109-122.

Reguillo, R. (2001). Emergencia de culturas juveniles. Buenos Aires: Norma.

Rodo, J. E. (1961). Ariel. México: Espasa-Calpe Mexicana.

SiLva, M. H.; SONNTAG, R. H. (1971). Universidad, dependencia y revolución. México: Siglo XXI. 
SOlARI, A. (1967). Los movimientos estudiantiles universitarios en América Latina. Caracas: Monte Ávila.

- (1971). Algunas reflexiones sobre la juventud latinoamericana. Santiago: CEPAL/ILPES.

SOlARI, A. y otros (1968). Estudiantes y politica en América Latina. Caracas: Monte Ávila.

VAsCONCElos, J. (1925). La Raza Cósmica. Barcelona.

- (1981) [1924]. «A los estudiantes de Trujillo que se dirigieron a mi en nombre de los estudiantes del Perú». En SkiRIUS, J. (ed.). El Ensayo hispanoamericano del siglo XX. México: Fondo de Cultura Económica (original revista Nosotros, Buenos Aires, 1924, no 178, p. 384-394).

Zemon-Davis, N. (1971). "The Reasons of Misrule: Youth Groups and Charivaris in Sixteenth-Century France». Past and Present, 50, I, p. 41-75.

Carles Feixa Pàmpols es doctor en antropología por la Universitat de Barcelona y profesor en la de Lleida. Ha investigado sobre cultura juvenil, antropología urbana, historia oral, hegemonía y violencia. En la actualidad, es vicepresidente del comité Sociología de la Juventud, de la Asociación Internacional de Sociología. Es autor de los libros De jóvenes, bandas y tribus (Barcelona, 1998), Culturas juveniles en México (México, 1998) y coautor de Jovenes na America Latina (Sao Paulo, 2004). Correo electrónico: Feixa@geosoc.udl.es

Yanko González Cangas es doctor en antropología por la Universidad Autónoma de Barcelona y profesor en la Universidad Austral de Chile. Ha trabajado en temas de desarrollo e intervención sobre juventud urbano-popular y rural, y publicado artículos sobre historia cultural de la juventud, crítica y representación etnográfica, entre otros. Es autor de los libros Metales pesados (1998); Héroes civiles \& Santos laicos (1999) y coautor de Jovens na América Latina (2004). Correo electrónico: ygonzale@uach.cl 